\title{
RELAÇÕES DE GÊNERO E ERGONOMIA: ABORDAGEM DO TRABALHO DA MULHER OPERÁRIA
}

\author{
Mislene A. G. ROSA ${ }^{*}$ e Raquel, QUIRINO \\ Centro Federal de Educação Tecnológica de Minas Gerais - CEFET-MG \\ misleneag@gmail.com
}

Submetido 30/06/2016 - Aceito 25/09/2017

DOI: $10.15628 /$ holos.2017.4772

\section{RESUMO}

Este artigo, de natureza teórica e empírica, descreve e aborda algumas condições de trabalho da mulher operária, sob a perspectiva de relações de gênero e intervenções ergonômicas. A partir da década de 1970, intensificou-se a participação da mulher no mercado de trabalho e, nos últimos anos elas deixaram de atuar somente naquelas áreas tipicamente femininas para ocupar espaço em profissões ditas masculinas que exigem força e resistência. O problema abordado são as dificuldades encontradas pelas mulheres operárias entrevistadas nesses ambientes laborais e a necessidade de adaptações ergonômicas dos postos de trabalho, de forma a atender as suas necessidades pessoais para a execução de suas atividades de forma eficiente e segura. Os resultados apontam para um silenciamento das relações de gênero no setor industrial, sobretudo quando se analisa as condições ergonômicas das atividades na perspectiva de uma subjetiva sexuada e atuante.

PALAVRAS-CHAVE: Relações de gênero, Trabalho, Ergonomia.

\section{GENDER RELATIONS AND ERGONOMICS: WOMAN'S WORK APPROACH WORKING}

\begin{abstract}
The purpose of this article, one of theoretical and empirical nature, is to examine the women's labor conditions, under the perspective of gender relations and ergonomic interventions. From the 1970's women's participation in the labor market intensified. In recent years they ceased to act exclusively in those areas stereotyped as female, to take up space in professions with prerequisites seen as male, strength and endurance. The main issues addressed were the
\end{abstract}

difficulties reported by women workers regarding work's organization and environment as well as ergonomic adaptation issues that meet their needs in order to achieve efficient and safe execution of their activities. The results point to a silencing of gender relations in this industrial segment, especially when analyzing the ergonomic conditions of the activities in a sexualized and active perspective.

KEYWORDS: Gender relations, Labour, Ergonomics. 


\section{INTRODUÇÃO}

Este artigo apresenta reflexões, apoiadas em fundamentos teóricos e empíricos, sobre as relações de gênero e ergonomia, sob o ponto de vista da mulher operária. Em seus limites, pretende analisar as principais dificuldades enfrentadas pelas mulheres, em áreas e profissões tipicamente masculinas, sob o aspecto ergonômico do trabalho.

A metodologia utilizada na pesquisa teve como base a realização de um levantamento do referencial teórico a partir de trabalhos científicos publicados, que discutem a inserção da mulher no mercado de trabalho, selecionando trechos de entrevistas realizadas por seus/as autores/as para correlacioná-los com a teoria estudada. Também foram realizadas observações diretas das atividades de trabalho de mulheres operárias, valorizando as informações obtidas em conversas informais assim como foram elaborados e posteriormente aplicados questionário para coleta de dados. A partir das falas dos/as entrevistados/as, buscou-se construir categorias de análises discutidas à luz do referencial teórico sobre ergonomia e divisão sexual do trabalho.

A fundamentação teórica buscou dados históricos sobre a divisão sexual do trabalho e a importância de estudos considerando as relações sociais de sexo/gênero como categoria analítica, assim como o conceito amplo de ergonomia, que engloba a ação ergonômica que se materializa em objetos (ferramentas, utensílios, vestuário, mobiliário) e em elementos organizacionais.

Os fundamentos empíricos, por sua vez, baseiam-se tanto em resultados de estudos de casos e entrevistas realizados pelos diversos autores citados nas referências, assim como, em questionários respondidos por mulheres operárias, seus gestores e observações de seus ambientes de trabalho.

Segundo Pereira (2003), a Ergonomia é o estudo científico da relação entre o/a trabalhador/a e o seu ambiente de trabalho e busca desenvolver a melhor maneira de executar um serviço, a utilização dos recursos mais apropriados, a organização dos procedimentos e do local de trabalho, assim como o uso correto e a manutenção dos equipamentos necessários à execução das tarefas, de modo a proteger a integridade física e mental do/a trabalhador/a.

Na década de 1970 observou-se um forte movimento de incorporação das mulheres no mercado de trabalho e, nos últimos anos, tem-se registrado a tendência do ingresso de mulheres em cargos tradicionalmente ocupados por homens. (Departamento Intersindical de Estatística e Estudos Socioeconômicos [DIEESE], 2012). No entanto a mera descrição de um cargo não equivale àquilo que realmente é feito pelo/a trabalhador/a, pois, a subjetividade humana faz com que, mesmo quando homens e mulheres exercem as mesmas atividades, as tarefas realmente realizadas na prática, são diferentes. Por isso a abordagem ergonômica, a partir da perspectiva de relações de gênero, torna-se fundamental para analisar as situações de trabalho, desvelando a vivência das trabalhadoras em relação à organização do trabalho e evidenciar aquilo que é fonte de pressões, de dificuldades e de desafios, suscetíveis de gerar o adoecimento e acidentes da mulher operária. 
Apesar de já estarem presentes em setores industriais tipicamente masculinos, tais como a mineração (Quirino, 2011) e a construção civil (Resende, 2012), as mulheres enfrentam, além das dificuldades culturais e sociais, as dificuldades de ordem física, por esses setores serem fundamentalmente assentados em atividades pesadas e que exigem força.

Nesse cenário é necessário discutir como a ergonomia pode contribuir para melhorar a qualidade de vida no trabalho em uma perspectiva de relações de gênero, porque, por mais que a igualdade de direitos seja respeitada, homens e mulheres têm subjetividades e necessidades biológicas distintas no ambiente laboral, quer seja nas condições ergonômicas, na organização do trabalho, ou na especificação dos Equipamentos de Proteção Individual (EPI) necessários à atividade desenvolvida.

\title{
2 DIVISÃO SEXUAL DO TRABALHO E RELAÇÕES DE GÊNERO: BREVES APROXIMAÇÕES TEÓRICO CONCEITUAIS
}

Hirata e Kergoat (2008) defendem que a divisão sexual do trabalho é resultante das relações sociais, que destinam aos homens o serviço produtivo e às mulheres o reprodutivo e, simultaneamente, a apropriação pelos homens das funções com maior valor social adicionado.

\begin{abstract}
A divisão sexual do trabalho é a forma de divisão do trabalho social decorrente das relações sociais entre os sexos; mais que isso, é um fator prioritário para a sobrevivência da relação social entre os sexos. Essa forma é modulada histórica e socialmente. Tem como características a designação prioritária dos homens à esfera produtiva e das mulheres à esfera reprodutiva e, simultaneamente, a apropriação pelos homens das funções com maior valor social adicionado (políticos, religiosos, militares, etc.) (Hirata \& Kergoat, 2008 p. 266).
\end{abstract}

Quanto ao emprego feminino, assiste-se mundialmente a um aumento do emprego e do trabalho remunerado das mulheres. No Brasil, segundo dados da Pesquisa Nacional por Amostra de Domicílios realizada em 2009 - PNAD/IBGE (DIEESE, 2012) a população feminina brasileira em idade ativa aproximava-se dos 84 milhões. Também o Informe de Previdência Social (MPS, 2015), conforme o gráfico 1, compara a evolução da participação da mulher no mercado de trabalho na condição de ocupada, entre 2001 e 2013. Observa-se um incremento na proporção de mulheres na população economicamente ativa - PEA. No entanto, de 2011 a 2013, há uma ligeira queda da participação das mulheres na PEA; esse fato demonstra que o ingresso feminino no mercado de trabalho não tem resultado em facilidades na manutenção de uma vaga, tanto que o desemprego feminino é maior do que o desemprego masculino assim como a precariedade do trabalho feminino é maior do que o masculino (Hirata, 2004). 


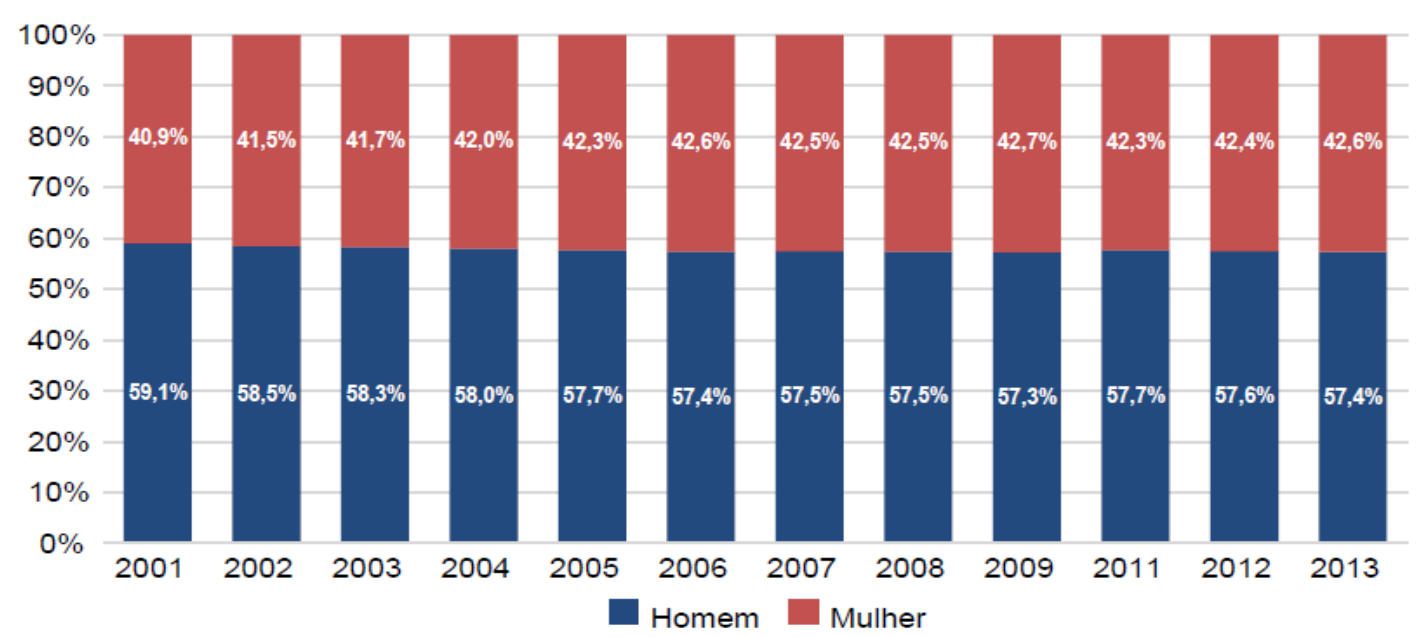

Gráfico 1: Evolução da Participação (\%) na População Ocupada Total, por Sexo - 2001 a 2013

Fonte: BRASIL. Informe de Previdência Social. (2015, p. 7)

Apesar da inserção feminina no mercado de trabalho, a estrutura de ocupação das mulheres se mostra diferente da ocupação masculina, os dados indicam que a mulher tende a reproduzir no mercado de trabalho as tarefas que realizam no próprio domicílio.

Hirata (2004) discute a questão da qualificação versus a competência na perspectiva de gênero. Para a autora todas as definições de competência fazem aparecer figuras e características masculinas: criatividade, responsabilidade, iniciativa, capacidades técnicas, autonomia no trabalho. As mulheres raramente estão presentes em cargos que requerem tais características. As competências ditas femininas não são reconhecidas nem remuneradas, são consideradas atributos naturais da mulher, na medida em que não foram adquiridas pela formação profissional.

No entanto, tal assertiva foi negada por Quirino (2011) quando, em sua pesquisa, constatou que as competências "ditas femininas" são extremamente valorizadas no mundo do trabalho da mineração. As evidências da autora mostram que gestores de áreas produtivas e de manutenção têm dado preferência à contratação de mulheres para operação de equipamentos pesados e para serviços de solda. Essa preferência se deve ao desenvolvimento tecnológico dos equipamentos que, pela alta tecnologia inserida, demanda toques mais deligados e precisos, além de zelo e limpeza das cabines e dos comandos. Em se tratando de trabalhos de soldagem, a habilidade manual fina também se faz necessária e, tais características são imputadas naturalmente às mulheres. Porém, não obstante a essa "pseudo valorização" das competências femininas, Quirino (2011) concluiu que tais habilidades, construídas nas relações sociais travadas no ambiente doméstico, não têm sido levadas em consideração para a promoção delas a cargos de comando, prestígio e poder.

Conforme verificado no gráfico 2 , as mulheres são a maioria de trabalhadores domésticos, com ou sem carteira de trabalho assinada, ocupações de baixa ou nenhuma remuneração, estes dados indicam uma marcada divisão sexual da precariedade. 


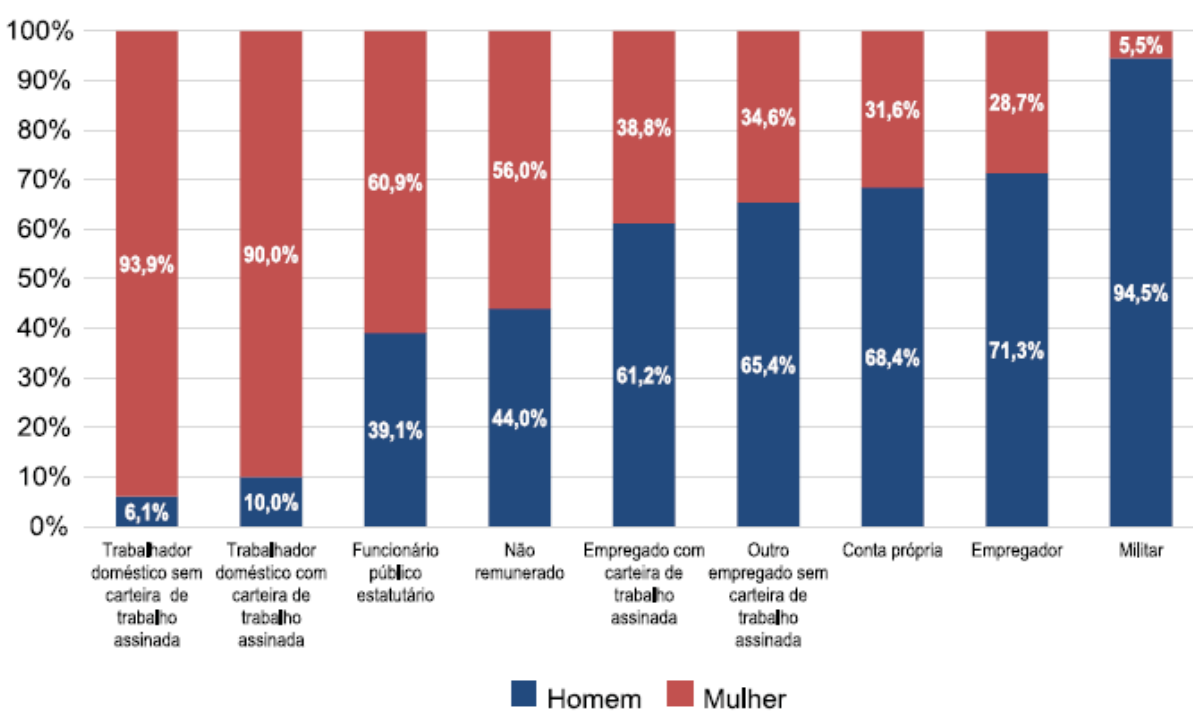

Gráfico 2: Proporção de homens e mulheres segundo posição na ocupação - 2013

Fonte: Informe da Previdência Social. Fev./2015. Volume 27, Número 02. (2015, p. 7)

A Tabela 1 apresenta a distribuição dos ocupados segundo o setor de atividade econômica, na qual se observa que as atividades econômicas que mais empregam mulheres são: serviço doméstico; comércio e reparação; educação, saúde e serviços sociais. Os dados confirmam a definição de Hirata (1995) que, no setor produtivo, as profissões que exigem força física e trabalhos pesados, realizados em ambientes inóspitos, sujos e insalubres, geralmente são associadas a estereótipos masculinos, visto que requerem coragem e determinação; ao passo que a feminilidade é associada ao trabalho leve, fácil, limpo, que exige paciência e minúcia, o que caracteriza a divisão sexual do trabalho.

\begin{tabular}{lcc}
\hline Setor de atividade econômica & Masculino & Feminino \\
\hline Administração pública & 5,4 & 4,8 \\
Agrícola & 20,5 & 12,2 \\
Alojamento e alimentação & 3,2 & 4,8 \\
Atividades mal definidas & 0,4 & 0,0 \\
Comércio e reparação & 18,5 & 16,8 \\
Construção & 12,6 & 0,5 \\
Educação, saúde e serviços sociais & 3,9 & 16,7 \\
Indústria de transformação & 14,9 & 12,4 \\
Outras atividades & 8,3 & 7,0 \\
Outras atividades industriais & 1,3 & 0,3 \\
Outros serviços coletivos, sociais e pessoais & 3,0 & 5,9 \\
Serviç̧os domésticos & 0,9 & 17,0 \\
Transporte, armazenagem e comunicação & 7,2 & 1,5 \\
Total & 100,0 & 100,0 \\
\hline
\end{tabular}

Tabela 1: Distribuição dos ocupados por sexo, segundo setor de atividade econômica.

\section{Brasil 2009 (em \%)}

Fonte: IBGE. Pnad. Elaborado por DIEESE (2012, p. 217) 
Embora haja o predomínio das mulheres nas áreas estereotipadas como femininas, destaca-se o expressivo percentual de mulheres ocupadas na indústria de transformação $(12,4 \%)$, setor tipicamente masculino. De acordo com NR 4 (MTE, 1983) que traz a relação da classificação nacional de atividades econômicas (CNAE) com correspondente grau de risco para fins de dimensionamento dos Serviços Especializados em Engenharia de Segurança e em Medicina do Trabalho (SESMT), a indústria de transformação engloba empresas com elevado grau de risco, o que demanda uma atenção maior para promover a saúde e proteger a integridade do/a trabalhador/a.

Portanto, analisar as condições ergonômicas sob o ponto de vista da mulher trabalhadora em empresas de grau de risco elevado, para identificar possíveis elementos discriminatórios na perspectiva de relações de gênero, torna-se importante para a promoção da igualdade de oportunidades entre homens e mulheres.

Dessa forma, a compreensão da divisão sexual do trabalho visa também auxiliar na construção de um diagnóstico ergonômico do sistema de trabalho, levando em consideração problemas como custo do adoecimento profissional; inadequação dos postos e dos ambientes de trabalho; qualidade insatisfatória dos produtos e dos processos de produção, entre outros.

\subsection{Ergonomia}

Conforme Daniellou, (2004) a ergonomia é ao mesmo tempo um conjunto de conhecimentos sobre o ser humano - fisiologia, psicologia, funcionamento cognitivo - e uma prática de ação, sendo assim pode-se entender a ergonomia como sendo o estudo científico da relação entre o/a trabalhador/a e seus meios, métodos e espaços de trabalho. Nesse sentido a Associação Brasileira de Ergonomia (ABERGO) (2000) sugere que a ergonomia objetiva modificar os sistemas de trabalho para adequar a atividade nele existente às características, habilidades e limitações das pessoas, com vistas ao seu desempenho eficiente, confortável e seguro.

Quanto ao risco ergonômico, Vidal (2010) o define como a condição ou a prática que traga obstáculos à produtividade, que desafie a boa qualidade ou que traga prejuízos ao conforto, segurança e bem estar do/a trabalhador/a.

Os trabalhos em Ergonomia têm uma dupla vertente: desde a redefinição de especificações da compra de mobiliário e ferramentas de trabalho - Ergonomia física; até a compreensão dos aspectos mentais da atividade de trabalho das pessoas, homens e mulheres. Um aspecto importante da Ergonomia é o posto de trabalho; suas ferramentas e elementos devem estar de acordo com as dimensões físicas do ocupante do posto de trabalho, pois, a inadequação antropométrica produz um desequilíbrio postural expondo o/a trabalhador/a à posições desconfortáveis, repetitividade dos gestos, maior esforço despendido, fatores causais das doenças ocupacionais (Vidal, 2010).

Todavia a organização do trabalho também deve ser considerada, entendendo a Ergonomia como uma "disciplina para ação sobre o real" (Antunes Lima, 2011, p.36). Em princípio, a Ergonomia organizacional encontraria muitas dificuldades, pois não está fundamentada numa objetividade plena, no entanto, constitui o campo no qual o/a 
trabalhador/a é percebido como um agente competente e organizado num sistema de produção, gerando assim maior satisfação no trabalho.

Para Marx (1867/1965), o trabalho é em essência um ato que se passa entre o homem e a natureza, o/a trabalhador/a transforma a natureza ao mesmo tempo autotransforma-se, como ser que trabalha. Em outras palavras, o trabalho se apresenta como elemento constituinte da essência humana, da experiência, do saber/aprender fazer de cada um. Portanto a subjetividade da Ergonomia organizacional torna-se igualmente importante para proporcionar condições adequadas de trabalho (Vieira, Barros, \& Antunes Lima, 2007, p.156).

Em sua atividade de trabalho o ser humano interage com os diversos componentes do sistema de trabalho, com os equipamentos, instrumentos, mobiliários e questões subjetivas como hierarquia e gestão organizacional. Sabe-se que os trabalhadores/as toleram mal as tarefas fragmentadas, com tempos curtos para execução, principalmente quando esse tempo é imposto por uma máquina ou pela gerência; sentem-se bem quando solicitado a resolverem problemas ligados à execução das tarefas; logo a Ergonomia busca tratar o/a trabalhador/a como um ser que pensa e age, não apenas como mero executor e extensão da máquina (Vidal, 2010).

\section{ADAPTAÇÃO DAS CONDIÇÕES DE TRABALHO}

Segundo Santos e Fialho (1998), postos de trabalho devem estar em harmonia com a característica física do ocupante. Também NR 17 (MTE, 1990), determina:

17.1. [...] parâmetros que permitam a adaptação das condições de trabalho às características psicofisiológicas dos trabalhadores, de modo a proporcionar um máximo de conforto, segurança e desempenho eficiente. (MTE, 1990).

Nesse sentido, o primeiro questionamento das empresas deveria ser: quem é este ou quem são esses/as trabalhadores/as para quem devo adaptar o posto trabalho?

Hirata e Kergoat (1994) afirmam que a classe operária tem dois sexos e tal afirmação contraria a tendência em apresentar uma imagem de classe operaria relativamente homogênea. As autoras defendem que as condições de trabalho dos trabalhadores e das trabalhadoras são quase sempre assimétricas, portanto analisar os postos de trabalho em termos de unidade de classe operária sem considerar o gênero poderá levar a um conhecimento falso das relações de trabalho.

Segundo dados empíricos da pesquisa de doutorado sobre o trabalho das mulheres na mineração realizada por Quirino (2011), o setor de mineração vem gradualmente inserindo mulheres em suas áreas técnico-operacionais. Conforme entrevista realizada pela autora com um Gerente de Recursos Humanos e um Diretor Operacional,

não há na empresa nenhuma formalização quanto à contratação de homens ou mulheres para quaisquer áreas ou funções. A decisão final é do gestor, dono da vaga. Na maioria das vezes é o supervisor que escolhe com quem quer trabalhar. A variável "sexo" não está presente nas formalizações de contratação da empresa. (Gerente de $\mathrm{RH})$

A adequação de espaços físicos não é justificativa para a não contratação de mulheres na indústria mineral. É preciso apenas definir diretrizes claras para contratação e adequação desses espaços. Quanto se tem o olhar voltado para os resultados, o que 
importa é o talento, a competência da pessoa. Não se é homem ou mulher. Os investimentos em espaços físicos adequados são mínimos quando comparados ao retorno que se pode obter. (Diretor Operacional)

A partir dos relatos dos entrevistados por Quirino (2011) há que se refletir até que ponto preocupações de natureza ergonômica se faz presentes nas políticas de contratação de mulheres pelas empresas. Constata-se que apesar de os entrevistados afirmarem que não existe impedimento para contratação de mulheres, a autora adverte que devido a inadequação dos espaços físicos tornou-se um hábito contratar apenas homens para as áreas operacionais (Quirino, 2011, p.75). O que, certamente, compromete a inserção das mulheres nesse setor produtivo.

\subsection{Organização do trabalho}

No item 17.6, da NR 17 (MTE, 1990), estabelece os parâmetros quanto à organização do trabalho:

17.6.1. A organização do trabalho deve ser adequada às características psicofisiológicas dos trabalhadores e à natureza do trabalho a ser executado.

17.6.2. A organização do trabalho, para efeito desta NR, deve levar em consideração, no mínimo:
a) as normas de produção;
b) o modo operatório;
c) a exigência de tempo;
d) a determinação do conteúdo de tempo;
e) o ritmo de trabalho;
f) o conteúdo das tarefas.

Diversos autores discutem sobre como a organização do trabalho interfere na qualidade de vida do/a trabalhador/a. Fatores relacionados ao tempo e ao ritmo de trabalho, intensos ou monótonos - e exigência de altos níveis de atenção e concentração para a realização das tarefas, combinados com níveis de pressão de supervisores por mais velocidade e produtividade, assim como a divisão e o parcelamento das tarefas causam, com frequência, doenças do sistema osteomuscular, ansiedade, estresse, distúrbios do sono e esgotamento profissional, dentre outras patologias.

A organização precária (exigência de tempo para realização do trabalho, ritmo acelerado na realização das atividades, divisão de tarefas - modelo taylorista-fordista) do trabalho afeta tanto os homens quanto as mulheres; no entanto é preciso analisar a incorporação da mulher no mercado de trabalho e sua relação com a tecnologia para compreender porque o trabalho precário atinge muito mais as mulheres do que os homens.

Segundo Toledo (2008), desde que a força motora necessária para a produção foi transferida dos músculos do trabalhador para a máquina, o caminho da incorporação das mulheres ao processo produtivo foi definitivamente aberto. Mas, para identificar a origem da feminização do trabalho, Hirata (2002) atribui à tecnologia a diminuição do esforço físico e a transformação das ferramentas que simplificam o trabalho, gerando, para as mulheres, 
empregos não-qualificados, predominantemente manuais, que exigem rapidez e destreza na execução de trabalhos minuciosos e monótono, qualidades ditas tipicamente femininas. Hirata (2003, p.14) constata também que as mulheres são mais pobre, mais precárias, mais desempregadas, têm menos acesso às novas tecnologias e menos acesso à formação profissional e técnica, embora desfrutem mais da educação hoje do que no passado. Tais fatos direcionam-se para uma marcada divisão sexual da precariedade, já que as mulheres são maioria nos trabalhos que exigem menores níveis de qualificação.

Em um estudo com trabalhadoras atendidas num serviço público de saúde, Neves (2006) demonstram que, quanto às lesões por esforço repetitivo e distúrbios osteomusculares (LER/DORT), existe diferença de prevalência significativa entre os gêneros, estando às mulheres entre a maioria dos casos. No entanto, ressalta que algumas pesquisas descrevem as mulheres como mais suscetíveis às LER/DORT partindo do pressuposto de que homens e mulheres estão expostos a mesma carga de trabalho.

Tal afirmação não condiz com a realidade, pois, mesmo quando exercem cargos iguais aos dos homens, as mulheres realizam atividades diferentes deles, além de estar sujeitas à dupla jornada de trabalho (no espaço público e no âmbito doméstico).

Assim, Hirata (2003) ressalta que é preciso considerar a relação entre os homens e as mulheres no universo doméstico, uma vez que o trabalho doméstico segue assumido integralmente pelas mulheres.

Diante dessa assertiva, em uma análise das características e limitações impostas pelas responsabilidades familiares da mulher, segundo dados do DIEESE (2012, p.227), a média de horas trabalhadas por homens é superior à das mulheres no mercado de trabalho; na família, no entanto, as mulheres trabalham, em média, três vezes mais do que o homem.

Hirata (1998, citada em Neves, 2006, p.2), descreve que as lesões por esforço repetitivo ou "doenças da hipersolicitação" são fruto do trabalho intenso e repetitivo, atingindo majoritariamente as mulheres. Essas lesões ocorrem maciçamente entre as trabalhadoras não por sua morfologia (30,0\% de massa muscular a menos) ou de fatores hormonais, incidindo sobre sua construção biológica e psicológica, mas por causa da organização do trabalho que as tratam como coisas, como máquinas.

Conforme entrevista realizada por Neves (2006):

na oficina, se você tiver que fazer 20 peças em tantos minutos, se você estiver com dor, a sua colega ao lado jamais irá pegar um peça sua para que você cumpra o seu horário, a sua produção, só para te ajudar. Não, ela vai fazer o possível e achar ótimo e fará tudo para que você perca o seu emprego e ela suba (trabalhadora) (Neves, 2006, p.3).

O autor identifica que as trabalhadoras, sujeitos de sua pesquisa, apresentavam características comuns aos elementos organizacionais presentes no seu trabalho. Muitas relataram que a repetitividade, a pressão por aumento na produção e a competitividade são fatores que intensificavam a dor e as lesões. Além das condições de trabalho serem extremamente precárias, a invisibilidade social destas mulheres cria barreiras para a produção de 
dados e informações que estabeleçam o nexo laboral, gerando um sentimento de impotência e a culpabilização das próprias trabalhadoras pelo adoecimento no trabalho.

\subsection{Condições Ambientais de Trabalho}

No item 17.5 da NR 17 (MTE, 1990), enumera as condições ambientais de trabalho:

17.5.1. As condições ambientais de trabalho devem estar adequadas às características psicofisiológicas dos trabalhadores e à natureza do trabalho a ser executado. (NR 17, 1990)

Segundo Mascia e Sznelwar (1996 citados no Manual de Aplicação da Norma Regulamentadora 17, [MTE] 2002, p.38), toda atividade de trabalho está inserida numa dada área, num dado espaço. $\mathrm{O}$ ambiente físico do trabalho pode favorecer ou dificultar a execução do mesmo. Seus componentes podem ser fonte de insatisfação, desconforto, sofrimento e doenças ou proporcionar a sensação de conforto.

Correlacionando o item acima, Resende (2012, p.22), discute a inserção de mulheres nos canteiros de obras da Construção Civil. Segundo a Norma Regulamentadora 18 (NR 18), referente às condições e meio ambiente de trabalho na indústria da Construção Civil, canteiro de obra é definido como "área de trabalho fixa e temporária, onde se desenvolvem operações de apoio e execução de uma obra". A autora questiona as entrevistadas sobre como é trabalhar no canteiro de obras na Construção Civil:

\footnotetext{
Facilidades tipo assim, a mulher ela é mais detalhista, entendeu? Então a gente para fazer um esquadro, para puxar um ponto de nível, a gente olha mais detalhe a gente faz a coisa mais bem feitinha, entendeu? Agora a dificuldade é a questão de peso, entendeu, porque você não pode escolher trabalho, entendeu? Hoje, você tá aqui tirando um pontinho, mas está chapando uma massa, entendeu? A dificuldade é o peso. (Pedreira)

[...] Meu marido acha um absurdo eu tá aqui trabalhando de servente. Ele tem vergonha de falar com os amigos dele que eu sou servente. Ele fala: "Minha esposa trabalha em uma obra aí". Não fala de quê. Ele não gosta. Ele bate o pé todo dia pra eu sair da obra. Ele acha que mulher tem de ficar dentro de casa, cuidando de filho, cuidando dele, e só ele que pode sair pra trabalhar. (Servente)

É, nós somos tratadas igual aos homens. Pelo menos nesta empresa é assim. Não tem distinção, não. Do jeito que são tratados os homens é tratado as mulheres. Da mesma forma. $[\ldots]$

O ponto fraco, você pega muito peso. É cansativo, né? É muito estressante. O ponto positivo, assim, é que você entra no mercado... mulher pedreira, gente é uma coisa do outro mundo. Você aprende coisas que você jamais sonharia em aprender, entendeu? O difícil mesmo é o peso. É mais pesado, entendeu? (Servente)
}

No que se refere às tarefas exercidas no canteiro de obras, os relatos citados estão de acordo com Tomasi (1999) quando enfatiza que as tarefas são perigosas, insalubres e demandam uma mão de obra jovem, forte, corajosa e de boa vontade não só para conviver com essas condições, como também para adquirir os conhecimentos necessários para a sua execução.

As entrevistadas também confirmam os pressupostos de Antunes (1999) ao afirmar que as empresas se apropriam intensificadamente da polivalência e multiatividade do trabalho feminino, da experiência que as mulheres trabalhadoras trazem das suas atividades realizadas na 
esfera do trabalho reprodutivo. Para o autor, ainda que não tenham consciência desse fato, as próprias trabalhadoras exaltam tais competências: detalhamento, agilidade, destreza, precisão, fineza, obediência, paciência, disciplina, responsabilidade, dedicação, delicadeza.

Enfim, as mulheres têm acesso a postos de trabalho tradicionalmente masculinos, mas as relações de trabalho aumentam a precariedade e a instabilidade de uma grande proporção da força de trabalho feminina, criam e/ou reproduzem condições de trabalho precarizada e um dos resultados desse processo é que para terem êxito na profissão a "mulher precisa ser considerada homem".Constata-se que não basta identificar as desigualdades, é preciso problematizar as relações sociais de sexo travadas no ambiente laboral de forma coerente e promover ações coordenadas para transformar as práticas sociais.

\subsection{Relatos das trabalhadoras, sujeitos da presente pesquisa sobre suas condições ambientais de trabalho}

Não obstante a regulamentação em segurança e saúde no trabalho quase sempre se refira a limites de tolerância que podem ser medidos objetivamente, o Manual de Aplicação da Norma Regulamentadora 17 de 2002 destaca a palavra "conforto". Ao trazer a palavra "conforto", a Norma Regulamentadora 17 torna imprescindível buscar a opinião do/a trabalhador/a acerca desse quesito em seu posto de trabalho.

Assim, optou-se pelo questionário como instrumento de coleta de dados para avaliar o nível de conforto das trabalhadoras em seus ambientes laborais. Para sua elaboração, foram consideradas questões que permitissem abordar as categorias de análises conforme o referencial teórico estudado. O questionário foi aplicado a trabalhadores/as de diversas áreas, em empresas diversas: engenharia, informática, comércio, mineração, etc. totalizando 43 respondentes, sendo 19 do sexo masculino e 24 do sexo feminino.

O questionário incluiu questões sobre pressão de supervisores e exigência de produtividade; interesse das empresas em oferecer as mulheres condições adaptadas aos postos de trabalho; acidentes de trabalho devido a condições inadequadas; Equipamentos de Proteção Individual (EPI) e ferramentas específicas para mulheres; uniforme para gestantes e uniformes femininos.

Conforme o gráfico 3, 76,4\% dos/as entrevistados/as responderam que a empresa na qual trabalham não oferece uniformes para gestantes, o que evidencia uma possível negligência das empresas diante das necessidades das mulheres.

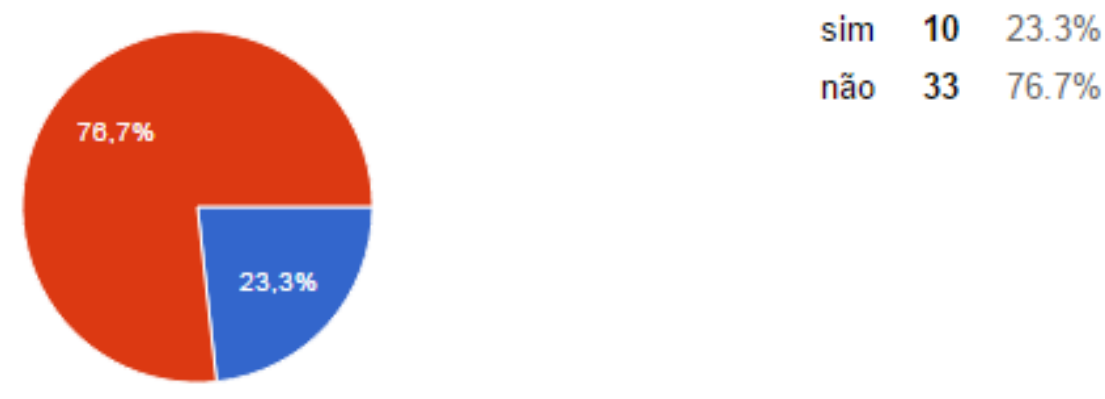

Gráfico 3: \% de empresa que fornecem uniformes para gestante.

Fonte: Dados do questionário elaborado pelas autoras. 
Ao questionar se possuíam todos os recursos e equipamentos adequados à execução de seu trabalho, os principais problemas foram quanto aos EPIs fornecidos. A maioria das mulheres relatou que utilizam uniformes masculinos (calças, jalecos e botina), reclamaram das luvas que, geralmente, são compradas no tamanho " $\mathrm{M}$ " e sempre ficam grandes dificultando o trabalho.

Eu sou uma mulher com menos de 1,60 $\mathrm{m}$ de altura e eu posso te dizer, não há uniforme no meu tamanho. Sempre uso calças masculinas, elas ficam grandes e desconfortáveis (Servente da construção civil).

Eu tenho muitas dificuldades em fornecer os meus trabalhadores EPI no tamanho adequado. Por facilidade a empresa compra os itens (luvas, uniformes, botinas, etc.) num tamanho médio. Neste caso as mulheres são as mais prejudicadas. (Gestor de obra civil)

Conforme Antunes Lima e Diniz (2007, p.57) vale destacar que o trabalhador médio não existe. O mesmo posto de trabalho ocupado por duas pessoas diferentes apresentará duas situações de trabalho específicas. A padronização pode resultar em desconforto e até doenças e acidentes de trabalho, principalmente se levar em consideração as diferenças antropométricas entre homens e mulheres.

Verifica-se pelos relatos doas/as entrevistados/as que as empresas não cumprem o disposto no item 17.4 da Norma Regulamentadora 17, a qual regulamenta que todos os equipamentos devem ser adequados às características dos/as trabalhadores/as. Assim como, também está em desacordo com o estabelecido na Norma Regulamentadora 6, item 6.4, a qual preconiza que o empregador deve fornecer aos trabalhadores os EPIs adequados.

As entrevistadas foram questionadas se já sofreram ou presenciaram situações de "assédio moral", pressão de supervisores e exigência de produtividade. Todas responderam, unanimemente, que existem cobranças excessivas e, quando as metas não são cumpridas, o gestor sempre relaciona a uma falta de competência, capacidade e inteligência das mulheres.

\begin{abstract}
As reuniões periódicas são cenários frequentes desse tipo de situação: novos procedimentos ou correções de procedimentos vigentes costumam ser transmitidos com ameaças de penalização. Erros presentes no dia a dia também são vias de represálias em tom agressivo para quem os comete. Outra situação é a perseguição clara de alguns funcionários por parte dos gestores. (Almoxarife)

O nível de pressão por resultados hoje é confundido com falta de respeito e desespero por alguns. Exposição de nomes em métodos comparativos. Ambientes de stress têm aumentado exponencialmente. (Projetista mecânica)
\end{abstract}

Segundo Vieira et al. (2007) o "assédio moral", geralmente percebido como dificuldades originadas nas relações humanas, na verdade têm sua origem em problemas na organização do trabalho (normas, conteúdo do trabalho, jornada, ritmo, comunicação, hierarquia) e frequentemente torna-se fonte de sofrimento e de atentado à saúde física e mental do/a trabalhador/a. Nesse contexto, enfatiza-se como dado importante mencionado pelas entrevistadas, que as questões organizacionais são um fator primordial quanto à análise do "conforto" e adequação do posto de trabalho. 


\section{CONSIDERAÇÕES FINAIS}

A finalidade deste artigo foi correlacionar as dificuldades relatadas por mulheres trabalhadoras com a classificação de riscos ergonômicos dos seus postos de trabalho. Compreendendo por risco ergonômico a condição ou a prática que traga obstáculos à produtividade, que desafie a boa qualidade ou que traga prejuízos ao conforto, segurança e bem estar do/a trabalhador/a, conforme já indicado no início deste artigo. Este trabalho buscou refletir sobre as peculiaridades do trabalho da mulher em ambientes geralmente associados a estereótipos masculinos.

A preocupação com a ergonomia nos ambientes de trabalho tem assumido relevância nas empresas, pois a definição da ergonomia coloca em primeiro plano seu objeto (interação trabalhador/a e atividade no contexto de trabalho) e seu objetivo de propor medidas concretas para uma melhor adaptação dos meios tecnológicos de produção e dos ambientes de trabalho, contribuindo para a produtividade e para a qualidade de vida do/a trabalhador/a.

A opção pelo estudo teórico e pesquisa qualitativa acerca dos temas necessários à compreensão do fenômeno estudado - relações de gênero no ambiente de trabalho e fatores ergonômicos -, permitiu identificar e analisar as percepções de mulheres sobre suas próprias condições de trabalho. Visa também contribuir para que ações promotoras de uma real adaptação das condições de trabalho às características psicofisiológicas dos trabalhadores, de modo a proporcionar um máximo de conforto, segurança e desempenho eficiente, sejam implantadas, conforme os parâmetros estabelecidos na Norma Regulamentadora 17. (MTE, 1990)

Segundo a Declaração dos Direitos e Princípios Fundamentais do Trabalho, diretrizes da Organização Internacional do Trabalho (OIT), a promoção da igualdade de oportunidades e a eliminação de todas as formas de discriminação são uma condição para o crescimento econômico do País. Assim como outras relações sociais, as relações de gênero são fatores muito importantes para garantir segurança e bem estar da "classe que vive do trabalho" (Antunes, 1999) e lograr mais justiça social.

\section{REFERÊNCIAS}

Abergo- Associação Brasileira de Ergonomia. (2000). A certificação do ergonomista brasileiro. Editorial do Boletim, 1.

Antunes, R. (1999). Os sentidos do trabalho: ensaio sobre a afirmação e a negação do trabalho. Boitempo Editorial.

Antunes Lima, F. P., \& Diniz, E.F. (2007). Novas tecnologias construtivas e acidentes na construção civil: o caso da introdução de um novo sistema de escoramento de formas de laje. Revista Brasileira de Saúde Ocupacional, 32(115).

Antunes Lima, F. P. (2011). Ergonomia, ciência do trabalho, ponto de vista do trabalho: a ciência do trabalho numa perspectiva histórica. Revista Ação Ergonômica, 1(2). 
Brasil. Ministério do Trabalho e Emprego [MTE]. (1983). Norma Regulamentadora Ministério do Trabalho e Emprego. NR-4: Serviço Especializado em Engenharia de Segurança e em Medicina do Trabalho.

Brasil. Ministério do Trabalho e Emprego [MTE]. (1990). Norma Regulamentadora Ministério do Trabalho e Emprego. NR-17: Ergonomia. 1990.

Brasil. Ministério do Trabalho e Emprego [MTE]. (2002) Manual de Aplicação da Norma Regulamentadora no 17. Brasília: MTE, SIT.

Brasil. Ministério da Previdência Social [MPS]. (2015). Informe de Previdência Social: A Mulher e a Previdência Social. 27(2)

Daniellou, F. (2004). A ergonomia em busca de seus princípios: debates epistemológicos. São Paulo: Edgard Blücher.

DIEESE - Departamento Intersindical de Estatística e Estudos Socioeconômicos (2012). A situação do trabalho no Brasil na primeira década dos anos 2000. São Paulo: DIEESE.

Hirata, H. \& Kergoat, D. (2008). Divisão sexual do trabalho profissional e doméstico: Brasil, França, Japão. Mercado de trabalho e gênero - comparações internacionais. Rio de Janeiro: Editora Fundação Getúlio Vargas, 263-178.

Hirata, H. (2004). O universo do trabalho e da cidadania das mulheres: um olhar do feminismo e do sindicalismo. Reconfiguração das relações de gênero no trabalho. São Paulo: CUT, 13-20.

Hirata, H. (2003). Por quem os sinos dobram?. Trabalho e Cidadania Ativa para as Mulheres, 15.

Hirata, H. (2002). Nova divisão sexual do trabalho?: um olhar voltado para a empresa e a sociedade. São Paulo: Boitempo.

Hirata, H. (1995). Relações sociais de sexo e do trabalho: contribuição à discussão sobre o conceito de trabalho. Em Aberto, Brasília-DF, 15-65.

Hirata, H., \& Kergoat, D. (1994). A classe operária tem dois sexos. Revista Estudos feministas, 2(3).

Neves, I. R. (2006). LER: trabalho, exclusão, dor, sofrimento e relação de gênero. Um estudo com trabalhadoras atendidas num serviço público de saúde. Caderno Saúde Pública, 22(6), 125765.

OIT, Organização Internacional do Trabalho. Igualdade de gênero e raça, erradicação da pobreza e geração de emprego. Disponível em: http://www.oit.org.br/content/genero-e-raca. Acesso em 09 set. 2015.

Pereira, E. R. (2003). Fundamentos de ergonomia e fisioterapia do trabalho. Rio de Janeiro: Taba Cultural. 
Quirino, R. (2011). Mineração também é lugar de mulher! Desvendando a (nova?!) face da divisão sexual do trabalho na Mineração de Ferro (Tese de Doutorado). Faculdade de Educação, Universidade Federal de Minas Gerais, (UFMG), Belo Horizonte, MG, Brasil.

Resende, M. C. (2012). Mulheres em ambientes masculinizados: análise da inserção de mulheres nos canteiros de obras da Construção Civil em duas empresas de Belo Horizonte (Dissertação Mestrado). Faculdade de Administração, Faculdade Novos Horizontes, Belo Horizonte, MG, Brasil.

Santos, N., \& Fialho, F. (1998). Manual de análise ergonômica do trabalho. Curitiba: Gênesis, 2, 316.

Toledo, C. (2008). Mulheres: o gênero nos une, a classe nos divide. São Paulo: Sundermann.

Tomasi, A. P. (1999). A construção social da qualificação dos trabalhadores da Construção Civil de Belo Horizonte: um estudo sobre os Mestres-de-Obras, Relatório de pesquisa-CNPq. Belo Horizonte, Fafich-UFMG.

Vidal, M. C. (2010). Introdução à ergonomia. Apostila do Curso de Especialização em Ergonomia Contemporânea/CESERG. Rio de Janeiro: COPPE/GENTE/UFRJ.

Vieira, C. E. C., Barros, V. A., \& Antunes Lima, F. P. (2007). Uma abordagem da Psicologia do Trabalho, na presença do trabalho. Psicologia em Revista, 13(1), 155-168. 